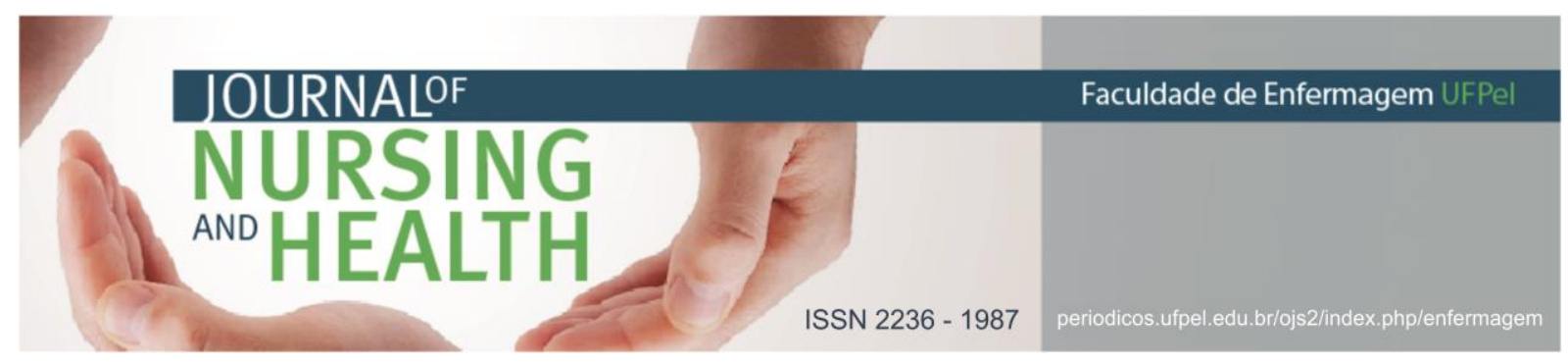

ARTIGO ORIGINAL

\title{
I Congresso Nacional de Ouvidores de Vozes no Brasil na perspectiva dos seus protagonistas
}

\author{
I National Congress of Hearing Voices in Brazil from the perspective of its \\ protagonists
I Congreso Nacional de Oyentes de Voces en Brasil en la perspectiva de sus protagonistas

Guedes, Ariane da Cruz¹; Riet, Helena Strelow²; Santos, Vinícius Boldt dos ${ }^{3}$

Como citar este artigo: Guedes AC, Riet HS, Santos VB. I congresso nacional de ouvidores de vozes no Brasil na perspectiva dos seus protagonistas. J. nurs. health. 2018;8(n.esp.):e188417

\section{RESUMO}

Objetivo: descrever a construção do I Congresso Nacional de Ouvidores de Vozes no Brasil, na perspectiva de seus organizadores. Métodos: pesquisa qualitativa, descritiva. A coleta de dados ocorreu durante o I Congresso Nacional de Ouvidores de Vozes, nos dias 20 e 21 de outubro de 2017, na cidade do Rio de Janeiro. Participaram oito organizadores do evento, o instrumento de coleta de dados foi a entrevista discursiva. Para a análise dos dados, realizou-se a análise temática de Minayo. Este estudo respeitou os princípios éticos da Resolução $n^{\circ}$ 466/2012 do Ministério da Saúde, sendo aprovado pelo Comitê de Ética em Pesquisa sob o parecer 2201138. Resultados: existe a preocupação com a participação dos experts por experiência e de demonstrar a relevância do tema para as novas práticas em saúde mental. Considerações Finais: perspectivas otimistas para futuros projetos na área colocam o Brasil entre os países engajados com essa abordagem humanizada.

Descritores: Saúde mental; Terapêutica; Impacto psicossocial; Sistemas de apoio psicossocial.

\section{ABSTRACT}

Objective: to describe the construction of the First National Congress of Hearing Voices in Brazil, from the perspective of its organizers. Methods: qualitative, descriptive research. Data collection took place during the First National Congress of Hearing Voices, on October 20 and 21, 2017, in the city of Rio de Janeiro. Participated eight event organizers and the instrument of data collection was discursive interview. For the analysis of the data, the thematic analysis of Minayo was carried out. This study respected the ethical principles of Resolution 466/2012 of the Ministry of Health, and was approved by the Research Ethics Committee under opinion 2201138. Results: there is concern about the participation of experts by experience to demonstrate the relevance of the theme to the new practices in mental health. Conclusion: optimistic perspectives for future projects in the area place Brazil among countries engaged with this humanized approach.

Descriptors: Mental health; Therapeutics; Psychosocial impact; Psychosocial support systems

1 Enfermeira. Doutora em Enfermagem. Universidade Federal de Pelotas (UFPEL). Email:arianecguedes@gmail.com. http://orcid.org/0000-0002-5269-787X

2 Bacharel em Psicologia. Universidade Federal de Pelotas (UFPEL). E-mail:helenarietpsico@gmail.com. http: / / orcid.org/0000-0001-5820-5242

3 Bacharel em Direito. Universidade Federal de Pelotas (UFPEL). Email:vini_boldt@yahoo.com.br. http://orcid.org/0000-0001-7067-7920 


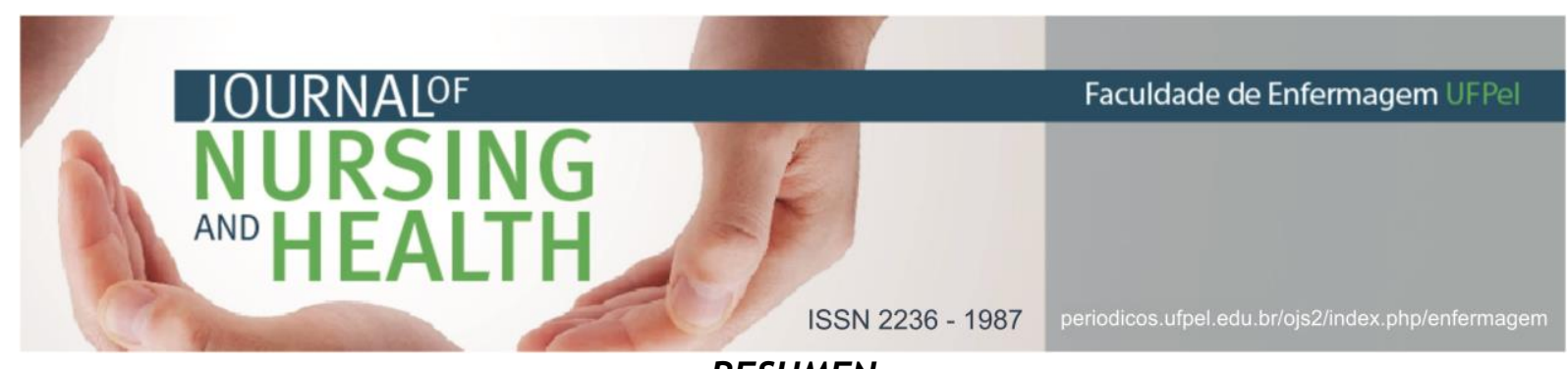

RESUMEN

Objetivo: describir la construcción del I Congreso Nacional de Oyentes de Voces en Brasil, en la perspectiva de sus organizadores. Métodos: investigación cualitativa, descriptiva. La recolección de datos ocurrió durante el I Congreso Nacional de Oyentes de Voces, en los días 20 y 21 de octubre de 2017, en la ciudad de Río de Janeiro. Participaron ocho organizadores del evento y el instrumento de recolección de datos fue entrevista discursiva y se realizó el análisis temático de Minayo. Este estudio respetó los principios éticos de la Resolución 466/2012 del Ministerio de Salud siendo aprobado por el Comité de Ética en Investigación bajo el dictamen 2201138. Resultados: existe la preocupación por la participación de los expertos por experiencia de demostrar la relevancia del tema para las nuevas prácticas en salud mental. Conclusión: perspectivas optimistas para futuros proyectos, en el área, colocan a Brasil entre países comprometidos con este enfoque humanizado.

Descriptores: Salud mental; Terapéutica; Impacto psicosocial; Sistemas de apoyo psicosocial.

\section{INTRODUÇÃO}

As discussões referentes a uma nova abordagem da temática de ouvir vozes iniciaram em 1987, quando o psiquiatra Marius Romme foi questionado pela paciente Patsy Hage sobre sua conduta em relação ao tratamento. As vozes que a paciente ouvia eram considerados sintomas negativos do processo de doença, mas - tratamento medicamentoso não apresentava resultados favoráveis. Após contato com outras pessoas que passaram pela experiência de ouvir vozes, a visão de Marius Romme sobre o tema começou a mudar e fundou-se uma organização para ouvidores de vozes, sendo que em 1987 surgiu o primeiro grupo de ouvidores de vozes, na Holanda, com o objetivo de que os ouvidores de vozes pudessem compartilhar suas experiências. ${ }^{1}$

No ano seguinte se estabeleceu o movimento de ouvidores de vozes no Reino Unido. Posteriormente o movimento se espalhou por outros países: Finlândia, Itália, Áustria, Portugal, Suécia, Gales, Escócia, Suíça, Alemanha, Japão, Noruega, Espanha, Dinamarca, Irlanda, Brasil e Grécia. Foi introduzido por Ron Colemann na Palestina, Nova Zelândia e Austrália e mais tarde chegou aos Estados Unidos e Canadá. Este movimento deu origem em 1996 a uma rede internacional de ouvidores de vozes, a The International Network for Training, Education and Research into Hearing Voices (INTERVOICE) e desde então são organizados congressos anuais. $^{1-2}$

Para a promoção e exposição de discussões sobre a temática de audição de vozes, formou-se uma organização, fundada por Marius Romme e Sandra Escher, com os objetivos de gerenciar as iniciativas que ocorrem em diversos países ao redor do globo e oferecer um suporte administrativo para que essas possam partir de um ponto em comum e se organizarem, esta organização é chamada de INTERVOICE. ${ }^{3}$

A INTERVOICE incorpora práticas e saberes de ouvidores de vozes, atingindo mais de trinta países, auxiliando na formação dos grupos de ouvidores de vozes e na divulgação dos eventos promovidos por estes mesmos grupos. $^{4}$

Anualmente a INTERVOICE organiza um Congresso Mundial sobre ouvir vozes, e o Dia Mundial de 


\section{JOURNALOF \\ NURSING

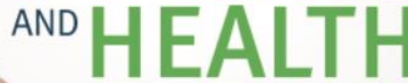

ISSN 2236 - 1987

Ouvidores de Vozes na data de 14 de setembro. Também criou em 2007 uma página na internet (http: Ilwww.intervoiceonline.org) para aproximar estudiosos e demais interessados no assunto. ${ }^{3}$

No Brasil a organização conta com um blog (intervoicebrasil.blogspot.com.br) e com movimentos em algumas cidades, como, por exemplo, Rio de Janeiro. ${ }^{5}$ Entre estes movimentos, merece destaque a construção e execução do I Congresso Nacional de Ouvidores de Vozes no Brasil, o qual ocorreu em 2017, na cidade do Rio de Janeiro, e reuniu muitos profissionais, estudiosos e usuários para debaterem a temática de forma aprofundada.

Diante dessa iniciativa pioneira, o presente artigo tem por objetivo descrever como se deu a construção do I Congresso Nacional de Ouvidores de Vozes no Brasil, na perspectiva de seus organizadores.

\section{MATERIAIS E MÉTODOS}

O presente estudo trata-se de uma pesquisa qualitativa, com abordagem descritiva, sendo um recorte da Pesquisa Ouvidores de Vozes - Novas Abordagens em Saúde Mental.

A coleta de dados ocorreu durante o I Congresso Nacional de Ouvidores de Vozes, que ocorreu nos dias 20 e 21 de outubro de 2017, na cidade do Rio de Janeiro. Participaram deste estudo oito organizadores do evento, e como instrumento de coleta de dados utilizaram-se entrevistas discursivas. ${ }^{6}$ Para a análise dos dados, utilizou-se a análise temática de Minayo. ${ }^{7}$
Este estudo respeitou todos os princípios éticos presentes na Resolução n 466/2012 do Ministério da Saúde $(M S)^{8}$, que estabelece as diretrizes e normas regulamentadoras de pesquisas envolvendo seres humanos, sendo que o projeto de pesquisa foi aprovado pelo Comitê de Ética em Pesquisa com Seres Humanos da Faculdade de Enfermagem da Universidade Federal de Pelotas sob o parecer $n^{\circ} 2.201 .138$.

Os organizadores do Congresso concordaram em divulgar a sua identidade, por meio da assinatura do Termo de Consentimento Livre e Esclarecido, autorizando a identificação de seus depoimentos em publicações científicas. Portanto, cada participante será identificado pelas iniciais do seu nome, sendo eles: Abmael de Souza Alves (ASA); Erotildes Maria Leal (EML); Henrique Campagnollo Dávila Fernandes (HCDF); Leonardo Duarte Bastos (LDB); Luciane Prado Kantorski (LPK); Octávia Cristina Barros (OCB); Octávio Domont Serpa Júnior (ODSJ) e Pablo Sade Valente (PS V).

\section{RESULTADOS E DISCUSSÃO}

Em setembro de 2009, na cidade de Maastricht, Holanda, foi realizado o $1^{\circ}$ Congresso Mundial de Audições, esse evento foi o responsável pela formação da INTERVOICE. No Congresso as apresentações abordaram temas como a experiência humana comum de ouvir vozes, o papel crucial da aliança terapêutica, trauma infantil, e a exploração de ouvir vozes.

$E$, oito anos após o primeiro Congresso Mundial de Ouvidores de Vozes, acontece no Brasil, no Instituto 


\section{JOURNALOF \\ NURSING \\ M०HEALTH}

ISSN 2236 - 1987

Existe uma aproximação entre as pessoas que ouvem vozes e participam dos grupos, onde conseguem ser eles mesmos sem medo dos rótulos classificatórios de doenças ou religião. A aproximação se dá tanto pela vontade de se auto ajudarem, quanto para auxiliarem na transformação da vida dos outros membros. ${ }^{5}$ Os profissionais atuantes nessa perspectiva também demonstram a vontade de dividir as experiências dessa nova abordagem.

Eu não vou dizer que é automaticamente, mas por existir uma empatia entre a gente, por uma série de questões e a partir desse fórum de saúde mental [...] congresso internacional $e$ fórum foram coisas a gente passou a pensar. (ASA)

Eu participei de alguns fóruns de saúde mental que o Centro Educacional Novas Abordagens Terapêuticas (CENAT) organizou [...] foi possivel achar interlocutores, outras pessoas, que queriam conhecer $e$ dividir essa perspectiva de lidar com a questão dos ouvidores de vozes. (LPK)

Ouvidores de vozes em geral são pessoas que sofrem com o estigma de serem considerados pessoas com transtornos psíquicos, cujo o ouvir vozes seria um sintoma. Quando encontram outros indivíduos na mesma situação e conseguem um diálogo livre desses preconceitos, eles costumam dar muito valor. 0 resultado disso é que os grupos de ouvidores de vozes, com essa abordagem, estão 


\section{JOURNALOF \\ NURSING \\ aNO HEALTH}

ISSN 2236 - 1987

Com

essas

iniciativas

dos ouvidores e profissionais da área, percebe-se a necessidade de criar espaços para aproximação e interação entre eles, nesse contexto os congressos são importantíssimos, ao conseguirem promover divulgação e compartilhamento de experiências ao redor do mundo, para que possa dar visibilidade e positivar as experiências dos ouvidores de vozes ${ }^{5}$, começam então os movimentos para a organização e o reconhecimento dos esforços empreendidos por aqueles que atuam na área.

Também experiências de pessoas que estavam trabalhando com grupos ou com abordagem de pessoas que ouvem vozes numa outra perspectiva. Então vem o pessoal do IPUB que foi $o$ trabalho pioneiro no Brasil, vem o pessoal de Brasília, vem o pessoal de Campinas, vamos nós de Pelotas aqui do Rio Grande do Sul e se reúnem essas pessoas, a gente acaba se conhecendo com essa mesma perspectiva, de fazer disseminar esse movimento dos ouvidores de vozes. (LPK)

O professor Paul Backer é fundamental nesse processo desde o começo de 2014, ele trazendo essa nova abordagem, $o$ jeito que ele fala, que ele explica, isso foi fundamental nesse processo. A professora Maria Tavares que cedeu o espaço, de ajudar na programação. 0 Abmael, 0 professor Octávio e a Octávia, também foram importantes em toda essa parte da organização. 0 


\section{ISSN 2236 - 1987}

Leonardo é muito engajado nesse processo. [...] a professora Luciane, também foi importante, não só na formação do congresso, mas no livro, do primeiro livro de ouvidores de vozes, tanto que foram vendidos cem exemplares no congresso, que mostra a ânsia das pessoas aprenderem, entenderem um pouco mais sobre o tema. (PSV)

Acho que seriam as pessoas que acabaram fazendo mais parte da formação desse congresso seria o professor Paul Backer, o Leonardo e o pessoal do Rio de Janeiro, a professora Maria Tavares, 0 Octávio, Abmael. (HCDF)

O protagonismo da formação de um Congresso de Ouvidores de Vozes no Brasil, país que está em um momento inicial nesta temática, se revela um desafio, mas ao mesmo tempo, uma possibilidade para que as pessoas que participam de grupos de ouvidores e estudiosos consigam debater e compartilhar seus conhecimentos, é um primeiro movimento que provavelmente dará bons frutos no futuro das discussões relacionadas.

Assim como eu participei de dois, três fóruns antes do congresso, várias outras pessoas que estavam no congresso participaram, em diferentes momentos, em diferentes estados, desses fóruns organizados pela CENAT que teve um papel determinante na construção desse congresso nacional. Primeiro porque ele marca o ingresso do Brasil na INTERVOICE, nessa rede do movimento de ouvidores de vozes. (LPK)

Então o congresso ele foi um momento ímpar, e dali eu acredito que deva reverberar tantas outras iniciativas em relação ao movimento dos ouvidores de vozes, as estratégias de cuidado, a perspectiva de empoderamento dessas pessoas que têm a expertise por experiência de serem ouvidores. Então acho que esse é o significado que eu vejo do Congresso Nacional de Ouvidores de Vozes, do primeiro, no Rio de Janeiro e da construção dos passos que vão se dar a seguir. (LPK)

Participação dos ouvidores de vozes

Observa-se nas falas a preservação do objetivo das primeiras iniciativas no trabalho com ouvidores de vozes, que tiveram como protagonistas os próprios ouvidores, trabalhando em parceria com profissionais, compartilhando e dando significados às suas vozes. ${ }^{10}$ Anteriormente interpretadas como sintomas patológicos pela psiquiatria tradicional que dominava o conhecimento sobre o assunto. 0 fato da participação e compartilhamento das experiências serem valorizados na construção deste congresso reforça os objetivos e a continuidade do trabalho de forma conjunta entre profissionais e experts por experiência, sendo os segundos fundamentais no 


\section{JOURNALOF \\ NURSING \\ AND}

ISSN 2236 - 1987

entendimento das características e peculiaridades que o processo envolve.

Os participantes destacaram a importância da troca de experiências e do trabalho a partir das experiências trazidas pelos próprios ouvidores, o que pode ser observado nas falas a seguir:

A minha preocupação o tempo inteiro num congresso, seja ele qual for [...] é com o familiar e o usuário. (ASA)

Então eu acho muito bom que a gente tenha conseguido ver isso, ver vários usuários que eu convivo aqui no dia-a-dia indo lá para frente falar, e acho que de alguma maneira isso expressa um pouco o esforço que a gente tem feito aqui. (ODSJ)

O Movimento de Ouvidores de Vozes traz ao longo do seu processo uma forte crítica à passividade do ouvidor de vozes e à dominância do saber profissional ${ }^{10}$, neste sentido, 0 fato dos profissionais demonstrarem preocupação com a participação dos experts por experiência e dos ouvidores de vozes na construção do movimento de ouvidores de vozes é importante e fundamental na construção desse processo no Brasil.

0 protagonismo dos experts por experiência e os interessados pela temática dos ouvidores de vozes, vem caminhando em direção a ressignificações no campo de entendimento nesta área, propondo uma nova abordagem no contexto da saúde mental. Esse processo depende da mobilização e construção de um novo olhar sobre o assunto, permeado pela desmistificação do conceito de patológico representado pelo ouvir vozes. ${ }^{11}$

Dessa forma, o movimento dos ouvidores de vozes pode ser comparado aos movimentos sociais, que através de mobilizações coletivas de indivíduos em busca da quebra de padrões estabelecidos conquistaram transformações culturais e políticas. E neste cenário, o movimento de ouvidores busca uma mudança e visibilidade das peculiaridades e singularidades que esta experiência representa para o ouvidor de vozes, deixando de lado o isolamento e a vitimização para ser protagonista da sua história e empoderar-se frente a esta vivência. ${ }^{10-11}$

A seguir alguns depoimentos dos entrevistados são relevantes na construção desse empoderamento e protagonismo, dando voz a quem de fato está vivendo a experiência e que poderá compartilhá-la de forma genuína.

[...] envolvimento pelo esforço que a gente tem feito para que essas pessoas possam estar de fato ali e se sentindo autorizadas a falar, alertando que o que elas têm a dizer merece ser ouvido. (ODSJ)

[...] trabalhando muito forte a questão do protagonismo e da expertise por experiência dessas pessoas. (LPK)

[...] para empoderar estas pessoas, para que elas tivessem mais liberdade [...] de falar sobre o que elas pensam, sobre o 


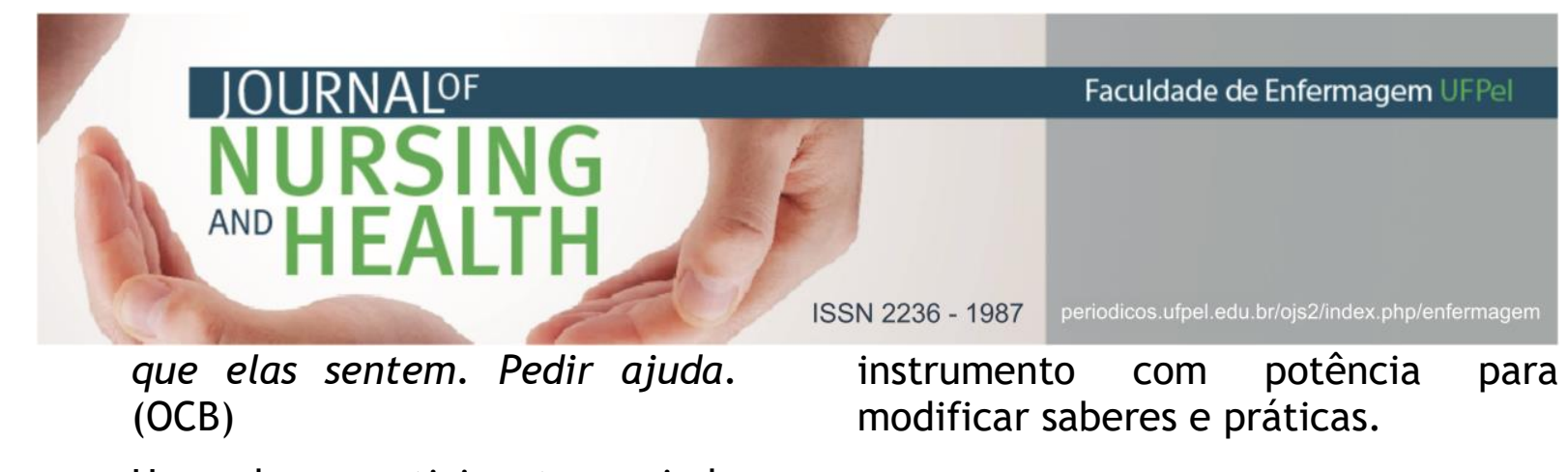

Um dos participantes ainda destacou a necessidade de tornar as produções sobre o tema dos ouvidores de vozes acessíveis a todos. Usando das ferramentas de tradução para outras línguas, para que trabalhos internacionais cheguem àqueles que têm interesse sobre o assunto e para que possa atingir o maior número de pessoas nos diversos países.

\section{[...] essa questão da tradução} que eu tenho muito claro que é muito importante, você tendo um livro, um ouvidor de voz em qualquer canto pode ler aquele livro, e aquilo vai reverberar. (LPK)

Tema inovador em meio à abordagem psiquiátrica tradicional

O movimento de ouvidores de vozes tem conquistado cada vez mais adeptos por se tratar de uma forma inovadora de lidar com as vozes. E a iniciativa de realização do I Congresso Nacional de Ouvidores de Vozes no Brasil foi um acontecimento emblemático para a divulgação do movimento, e principalmente para a quebra de paradigmas, pelo fato de que até então, a experiência de ouvir vozes era considerada somente um sintoma psiquiátrico, que deveria receber tratamento psiquiátrico.

Por meio da possibilidade de promover um espaço de diálogo entre ouvidores de vozes, familiares e profissionais, promoveu-se muito mais do que um congresso, mas um

Então assim, eu fico muito feliz de ver como expandiu aqui no Brasil e até então isso era muito novo. [...] E hoje eu vejo assim, auditório lotado, várias experiências no Sul, do estado, nossa eu fiquei muito feliz [...] de ver como as pessoas foram tomadas por essa idéia, por essa nova abordagem, acho que é muito gratificante. (OCB)

O que me chamou a atenção nesse congresso e me chama a atenção como esse tema, captura, num bom sentido... [...] ele é um chamarisco de profissionais. Mas me chama atenção o número pequeno de produção dos usuários pelos usuários. [...] mas uma certa ideia de empoderamento do paciente que eu não sei se está presente na nossa rede. (EML)

Um dos organizadores refere a sua preocupação com a participação dos usuários, mas que para isso será necessário trabalhar o empoderamento desses na rede de saúde. Sendo que o principal foco dos Congressos de Ouvidores de Vozes deve ser os ouvidores, os quais são experts por experiência.

Outra questão importante considerada por uma das organizadoras é o compromisso que os profissionais devem ter em expandir as novas abordagens do ouvir vozes para os serviços de saúde mental, sendo que os participantes do congresso passam a ser multiplicadores dessa nova possibilidade de abordagem: 


\section{ISSN 2236 - 1987}

Ficou bem claro a partir da voz de uma mãe ali, que, não adianta você vir só no congresso, você tem que expandir para os serviços, essas novas abordagens, que os profissionais também tenham esse olhar de acolher [...] Eu escuto vozes? Mas não é só pela via da medicação, medicação é importante sim, mas assim, aliar isso a outras estratégias que nós profissionais que estamos no campo da saúde mental podemos ofertar, podemos acolher esta pessoa $e$ divulgar isso em todos os serviços de saúde mental. (OCB)

Espera-se que o I Congresso Nacional de Ouvidores de Vozes no Brasil seja um disparador para o empoderamento dos ouvidores de vozes, tornando singular e única a abordagem de suas experiências. $E$ que os serviços de saúde possam acolher as novas abordagens, avançando suas ações para o cuidado em liberdade, livre de estigmas.

\section{CONSIDERAÇÕES FINAIS}

É importante lembrar que a experiência de ouvir vozes pode ser muito dolorosa, perturbadora ou até mesmo desesperadora. A ideia bastante difundida de que os profissionais de saúde têm como objetivo a erradicação das vozes, aliado ao fato de que o fenômeno não costuma ser visto socialmente de forma positiva em nossa cultura, pode estimular $o$ isolamento e tornar a vivência do processo muito solitária. Apoiar e acolher essas pessoas em seu sofrimento é um passo importante na construção de modos de cuidado mais humanos, contribuindo para mudar a forma como a sociedade trata essa dimensão.

Diante da compreensão trazida pelos protagonistas na construção do I Congresso Nacional dos Ouvidores de Vozes no Brasil, por meio de seus depoimentos, fica nítido o engajamento dos organizadores em fazer o tema dos ouvidores de vozes reverberar no país. Existe a preocupação com a participação ativa dos experts por experiência e de demonstrar a relevância do tema para a inserção de novas práticas em saúde mental, resultando em perspectivas otimistas para futuros projetos na área e colocando, dessa forma, o Brasil no mapa dos países engajados com esta abordagem humanizada.

\section{REFERÊNCIAS}

1 Escher S, Romme M. The hearing voices movement. In: Blom JD, Sommer IEC, editores. Hallucinations research and practice. New York: Springer; 2012:385-93.

2 Romme M, Escher S. Na companhia das vozes: para uma análise de experiência de ouvir vozes. Lisboa: Editorial Estampa; 1997.

3 Barros OC, Serpa Júnior O D de. Ouvir vozes: um estudo sobre a troca de experiências em ambiente virtual. Interface comun saúde educ [Internet]. 2014 [acesso em 2018 ago 11];18(50):557-69. Disponível em: http://www.scielo.br/pdf/icse/v18n5 0/1807-5762-icse-1807-

576220130680.pdf

4 Kantorski L, Andrade APM. Assistência psiquiátrica mundo afora: práticas de resistência e garantia de 


\section{JOURNALOF \\ NURSING \\ ${ }^{\text {AND HEALTH }}$}

direitos. Cadernos brasileiros de saúde mental [Internet]. 2017 [acesso em 2018 ago 31];9(24):50-72. Disponível em:

http:/ / incubadora.periodicos.ufsc.br/ index.php/cbsm/article/view/4979/5 108

5 Kantorski LP, Antonacci MH, Andrade APM, Cardano M, Minelli M. Grupos de ouvidores de vozes: estratégias e enfrentamentos. Saúde debate [Internet]. 2017 dez[acesso em 2018 abr 05];41(115):1143-55. Disponível em:

http:/ / www.scielo.br/scielo.php?scrip $\mathrm{t}=\mathrm{sci}$ arttext\&pid=S0103$11042017000401143 \& \operatorname{lng}=e n$.

6 Cardano M. Manual de pesquisa qualitativa: a contribuição da teoria da argumentação. $1^{\text {a }}$ ed. Petrópolis: Vozes; 2017.

7 Minayo MCS. 0 desafio do conhecimento: pesquisa qualitativa em saúde. $2^{\text {a }}$ ed. São Paulo: Hucitec; 2010.

8 Ministério da Saúde (BR). Conselho Nacional de Saúde. Resolução 466, de 12 de dezembro de 2012: diretrizes e normas regulamentadoras de pesquisa envolvendo seres humanos. Brasília; 2012.

9 Ruddle A, Mason O, Wykes T. A review of hearing voices groups: evidence a. clinical psychology review. Nova lorque [Internet]. 2011 July [cited 2018 Apr 05]; 31(5):757-766. Avalaible from: https://www.ncbi.nlm.nih.gov/pubm ed/21510914.

10 Longden E, Corstens D, Dillon J. Recovery, Discovery and revolution: the work of intervoice and the hearing voices movement. In: Coles $\mathrm{S}$, Keenan S, Diamond B, editores. Madness
ISSN 2236 - 1987

contested: power and practice. Rosson-Wye: PCCS Books; 2013. p. 161-80.

11 Corstens D, Longden E, McCarthyJone S, Waddingham R. Thomas $\mathrm{N}$. Emerging perspectives from the hearing voices movement: implications for research and practice. Schizoph bull [Internet]. 2014 [cited 2018 Aug 20];40(4):285-94. Available from: https: / /www.ncbi.nlm.nih.gov/pmc/a rticles/PMC4141309/

Data de publicação: 19/09/2018 